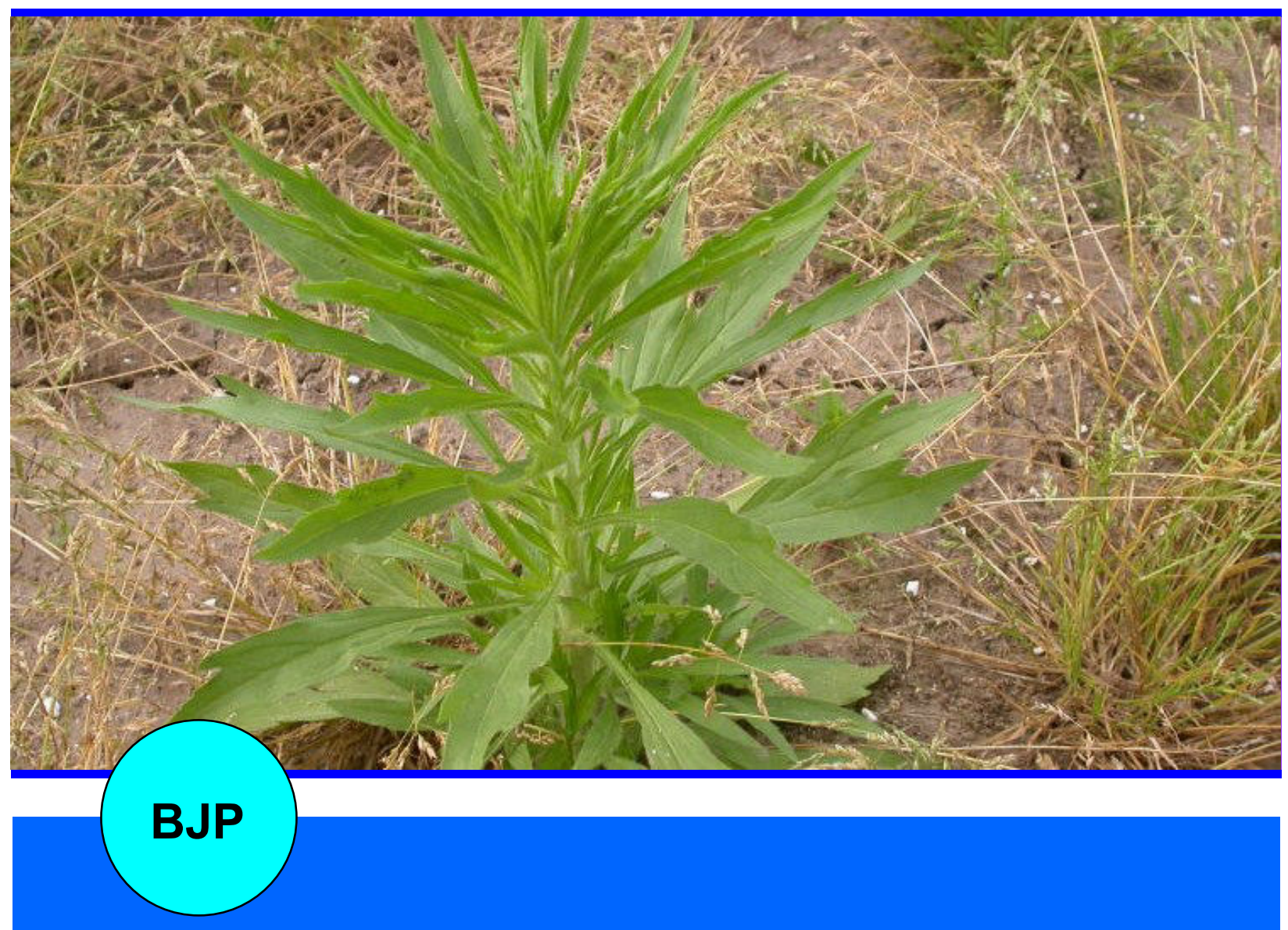

Bangladesh Journal of Pharmacology

Research Article

Isolation and antifungal screening of endophytic fungi from Erigeron canadensis 
Abstracted/indexed in Academic Search Complete, Asia Journals Online, Bangladesh Journals Online, Biological Abstracts, BIOSIS Previews, CAB Abstracts, Current Abstracts, Directory of Open Access Journals, EMBASE/Excerpta Medica, Global Health, Google Scholar, HINARI (WHO), International Pharmaceutical Abstracts, Open J-gate, Science Citation Index Expanded, SCOPUS and Social Sciences Citation Index;

ISSN: $1991-0088$

\title{
Isolation and antifungal screening of endophytic fungi from Erigeron canadensis
}

\author{
Xuelian Bai ${ }^{1}$, Ting Zhou ${ }^{1}$, Tongfei Lai ${ }^{1}$, Yicong $\mathrm{Li}^{1}$, Jiale Chai ${ }^{1}$, Jiajun $\mathrm{Ni}^{1}{ }^{\text {and }}$ \\ Huawei Zhang² \\ ${ }^{1}$ College of Life and Environmental Sciences, Hangzhou Normal University, Hangzhou 310036, P. R. China; \\ ${ }^{2}$ School of Pharmaceutical Sciences, Zhejiang University of Technology, Hangzhou 310014, P. R. China.
}

\begin{tabular}{|c|c|}
\hline \multicolumn{2}{|l|}{ Article Info } \\
\hline Received: & 9 April 2017 \\
\hline Accepted: & 5 June 2017 \\
\hline Available Online: & 16 July 2017 \\
\hline \multicolumn{2}{|c|}{ DOI: 10.3329/bjp.v12i3.32126 } \\
\hline $\begin{array}{l}\text { Cite this article: } \\
\text { Bai X, Zhou T, Lai } \\
\text { Zhang H. Isolati } \\
\text { screening of end } \\
\text { Erigeron canaden } \\
\text { Pharmacol. 2017; }\end{array}$ & $\begin{array}{l}\text { Y, Chai J, Ni J, } \\
\text { hd antifungal } \\
\text { c fungi from } \\
\text { 3angladesh J } \\
-59 \text {. }\end{array}$ \\
\hline
\end{tabular}

\begin{abstract}
Sixteen fungal strains isolated from the Erigeron canadensis, one of traditional Chinese medicines used to treat the pathogenic infection and dysentery, were evaluated for their antifungal activities against one human pathogen Candida albicans, and two phytopathogens, Colletotrichum fructicola and Rhizoctonia cerealis. The bioassay results indicated that the ethyl acetate extract of the fermentation broth of these fungal endophytes had stronger antimicrobial activities. Among these endophytic strains, the ethyl acetate extracts of strains NPR003 and NPR005 showed the strongest inhibitory effects and has potential application in the discovery of new antifungal agents. This was the first report on the isolation of endophytic fungi from E. canadensis and evaluation of their antifungal activities.
\end{abstract}

\section{Introduction}

Fungal infection is an important life-threatening disease, which annually causes the death of millions of people (Xie et al., 2014) and the great loss of crop production (Bennett et al., 2012). Effective and efficient control of fungal pathogens can be achieved by the use of chemically synthetic fungicides. However, a limited repertoire of eco-friendly and low toxic antifungals are used all over the world. Thus, there is an urgent need to search for alternative approaches to accelerate the discovery of more biocontrol agents to treat fungal infections and their drug resistance. A growing evidence indicates that endophyte, a special microbial community colonized in healthy plants, is one of the rich sources of bioactive natural products with great potential application in the fields of medicine and agriculture (Zhang et al., 2006; 2014). Isolation and antifungal evaluation of endophytic microbe would provide a better alternative way to identify novel antifungal agents.
Erigeron canadensis Linn., called horseweed widely distributed in China, is one of the herbaceous Chinese medicines used to treat intestinal diseases (Park et al., 2013; Wu et al., 2015). Modern pharmacological study showed that E. canadensis has strong bioactivties, including anti-inflammation (Sohn et al., 2009; Sung et al., 2014), anticoagulant and antiplatelet activity (Pawlacyk et al., 2011), inhibition of melanogenesis (Hong et al., 2008), cytotoxicity (Choi et al., 2008) and antifungal activity (Curini et al., 2003). Up to now, however, there is no report on biology and chemistry of endophytic microbes from this medicinal plant. In our continuous investigation of antimicrobial fungi derived from the plants (Zhang et al., 2012; 2014; 2015), 16 endophytic strains (numbered as NPR001-NPR016) were isolated from E. canadesis and evaluation of their antifungal effects was carried out in this work.

\section{Materials and Methods}

The healthy plant of E. canadensis was obtained from the 
Xiasha campus of Hangzhou Normal University, Hangzhou, China and used for the endophyte isolation within 48 hours after harvest. Three testing fungal pathogens, including one human pathogen, Candida albicans, and two plant pathogens, Colletotrichum fructicola and Rhizoctonia cerealis, were from China Center for Type Culture Collection (CCTCC). All chemicals used in this project were of analytical grade.

\section{Isolation of endophytic strain}

Endophytic fungal strains from E. canadensis were isolated according to our reported procedure (Zhang et al., $2012 ; 2014 ; 2015)$. All these fungal strains were transferred into potato dextrose agar (PDA) slants followed by storing at $4^{\circ} \mathrm{C}$.

\section{Fermentation and preparation of ethyl acetate extract} of fungal endophyte

Each fungal strain was cultured on PDA at $28^{\circ} \mathrm{C}$ for 7 days. Then a balanced amount of fungal colony was transferred to culture broth in a $500 \mathrm{~mL}$ erlenmeyer flask, which contained $200 \mathrm{~mL}$ sterilized potato dextrose broth (PDB) followed by shaking at $150 \mathrm{rpm}$ for 15 days at $28^{\circ} \mathrm{C}$. By the end of fermentation, the mycelium and the culture broth were separated by centrifugation at $4,500 \mathrm{rpm}$ for $15 \mathrm{~min}$ at $4^{\circ} \mathrm{C}$. The fermentation broth was extracted twice with $400 \mathrm{~mL}$ ethyl acetate (Merck). Then the upper solvent was evaporated at $20^{\circ} \mathrm{C}$ in vacuum to yield the ethyl acetate extract, which possibly had antimicrobial substances metabolized by fungal endophyte. Each afforded extract was kept in a vacuum drier for 3 days and dissolved in dimethyl sulfoxide (DMSO, Merck) before bioassay. The final concentration of each ethyl acetate extract had three levels, including $0.1,1,10 \mathrm{mg} / \mathrm{mL}$.

\section{Antifungal test}

The antifungal assay was carried out using disc diffusion method (Zhang et al., 2012; 2014; 2015). Three fungal blocks of C. albicans, C. fructicola and $R$. cerealis were respectively transferred into three $500 \mathrm{~mL}$ erlenmeyer flasks, each flask had $200 \mathrm{~mL}$ sterilized PDB. The seed liquid was prepared after incubation at $28^{\circ} \mathrm{C}$ on a rotary shaker at $150 \mathrm{rpm}$ for 3 days. Firstly, 5 $\mathrm{mL}$ melt water agar (WA) medium was evenly poured into petri dishes $(\Phi=90 \mathrm{~mm})$. Secondary, $200 \mu \mathrm{L}$ seed liquid was added to fresh NA medium and mixed well. Thirdly, the same amount of fresh NA medium was poured on the solidified WA medium and the testing plate with double medium for antifungal bioassay was prepared. After 5 holes $(\Phi=6 \mathrm{~mm})$ were equidistantly drilled on inoculated media, a piece of standard sterile filter paper $(\Phi=6 \mathrm{~mm})$ was put in one hole followed by adding $100 \mu \mathrm{L}$ ethyl acetate extract of endophytic fungal strain. Amphotericin B (30 $\mu \mathrm{g} /$ disk, SigmaAldrich) was used as the positive control and the pure DMSO or sterilized water was the negative control. The diameter of inhibition zone (in $\mathrm{mm}$ ) was measured to assess antifungal activity. All tests were carried out in triplicate.

\section{Results}

Biological investigation of endophytic fungi from healthy E. canadensis lead to isolation of sixteen fungal strains (NPR001-NPR016), which seven stains NPR001NPR007 were from roots, two strains NPR008-NPR009 from flowers, five strains NPR010-NPR014 from stems, and two strains NPR015-NPR016 from leaves. The antifungal bioassay results were shown in Table I.

The ethyl acetate extracts of endophytic fungi had different inhibitory effect on fungal pathogens, including $C$. albicans, $C$. fructicola and $R$. cerealis. Generally, their antifungal activities were in a concentration-dependent manner. Among these fungal endophytes, two strains NPR003 and NPR005 had a broad spectrum of antifungal activities against all testing pathogens. As far as the human fungal pathogen C. albicans concerned, 7 strains NPR003-NPR005, NPR007, NPR009, NPR012 and NPR013 exhibited stronger inhibitory effect than others at the same concentration. Five endophytic strains (NPR003, NPR005, NPR006, NPR010 and NPR015) and 2 strains (NPR001 and NPR005) showed potent activity against C. fructicola and R. cerealis, respectively.

\section{Discussion}

According to symbiosis theory, endophytic microbe has the ability to biosynthesize some 'phytochemicals' originally from their host plants (Zhang et al., 2014). A growing evidence suggests that fungal endophytes are widely distributed in healthy plant organs and have abundant biodiversity and chemodiversity. Bioactive extracts and natural products derived from endophytic fungi would effectively accelerate new drug discovery and contribute to the development of green agriculture.

In the present work, sixteen fungal strains (coded as NPR001-NPR016) were characterized from E. canadensis Linn. Bioassay results showed that the ethyl acetate extracts of strains NPR003 and NPR005 exhibited potent inhibitory effects on all test pathogens, which were in a concentration-dependent manner. It also indicated that strains NPR003 and NPR005 were the best biocontrol candidates and had potential application in medicine and pesticide industry.

Up to now, strains NPR003 and NPR005 were respectively identified as Alternaria spp., Aspergillus spp. by $18 \mathrm{~S}$ rDNA sequence analysis and morphological properties. Bioassay-guided fractionation of the ethyl acetate extracts of the scale-up fermentation broth of 
Table I

\section{Antifungal activities of ethyl acetate extracts of endophytic fungi from Erigeron canadensis}

\begin{tabular}{|c|c|c|c|c|}
\hline \multirow{2}{*}{ Strain No. } & \multirow[t]{2}{*}{ Concentration $\mathrm{mg} / \mathrm{mL}$} & \multicolumn{3}{|c|}{ Antifungal effects } \\
\hline & & Candida albicans & Colletotrichum fructicola & Rhizoctonia cerealis \\
\hline \multirow[t]{3}{*}{ NPR001 } & 0.1 & - & - & - \\
\hline & 1 & - & - & + \\
\hline & 10 & + & + & ++ \\
\hline \multirow[t]{3}{*}{ NPR002 } & 0.1 & - & - & - \\
\hline & 1 & + & - & - \\
\hline & 10 & + & + & + \\
\hline \multirow[t]{3}{*}{ NPR003 } & 0.1 & + & + & - \\
\hline & 1 & ++ & ++ & + \\
\hline & 10 & +++ & ++ & ++ \\
\hline \multirow[t]{3}{*}{ NPR004 } & 0.1 & - & - & - \\
\hline & 1 & + & - & + \\
\hline & 10 & ++ & - & + \\
\hline \multirow[t]{3}{*}{ NPR005 } & 0.1 & + & + & + \\
\hline & 1 & ++ & ++ & ++ \\
\hline & 10 & +++ & +++ & +++ \\
\hline \multirow[t]{3}{*}{ NPR006 } & 0.1 & - & - & - \\
\hline & 1 & - & + & - \\
\hline & 10 & - & ++ & + \\
\hline \multirow[t]{3}{*}{ NPR007 } & 0.1 & + & - & - \\
\hline & 1 & ++ & - & - \\
\hline & 10 & ++ & + & - \\
\hline \multirow[t]{3}{*}{ NPR008 } & 0.1 & - & - & - \\
\hline & 1 & - & - & - \\
\hline & 10 & + & - & + \\
\hline \multirow[t]{3}{*}{ NPR009 } & 0.1 & + & - & - \\
\hline & 1 & ++ & - & - \\
\hline & 10 & ++ & + & + \\
\hline \multirow[t]{3}{*}{ NPR010 } & 0.1 & - & - & - \\
\hline & 1 & - & + & + \\
\hline & 10 & - & ++ & + \\
\hline \multirow[t]{3}{*}{ NPR011 } & 0.1 & - & - & - \\
\hline & 1 & - & - & - \\
\hline & 10 & + & + & - \\
\hline \multirow[t]{3}{*}{ NPR012 } & 0.1 & - & - & - \\
\hline & 1 & ++ & + & - \\
\hline & 10 & ++ & + & + \\
\hline \multirow[t]{3}{*}{ NPR013 } & 0.1 & + & - & - \\
\hline & 1 & + & - & + \\
\hline & 10 & ++ & + & + \\
\hline \multirow[t]{3}{*}{ NPR014 } & 0.1 & - & - & - \\
\hline & 1 & - & - & - \\
\hline & 10 & - & - & - \\
\hline \multirow[t]{3}{*}{ NPR015 } & 0.1 & + & - & - \\
\hline & 1 & + & + & - \\
\hline & 10 & + & ++ & + \\
\hline \multirow[t]{3}{*}{ NPR016 } & 0.1 & - & - & - \\
\hline & 1 & - & - & - \\
\hline & 10 & + & - & + \\
\hline Amphotericin B & $30 \mu \mathrm{g} /$ disk & ++++ & ++++ & ++++ \\
\hline DMSO & & - & - & - \\
\hline
\end{tabular}

aExpressed by the diameter of inhibition zones: -, no inhibition;,$+<10 \mathrm{~mm} ;++, 10-15 \mathrm{~mm} ;+++, 16-20 \mathrm{~mm} ;++++,>20 \mathrm{~mm}$ 
strain NPR003 led to the isolation of five tricycloalternarene (TCA) analogs, which had antimicrobial and cytotoxic effects (Wang et al., 2013). Our findings would supply an important reference to discover a new source of TCA compounds as antimicrobial agents.

\section{Conclusion}

This was the first report on isolation and evaluation of antimicrobial effect of endophytic fungi from $E$. canadensis.

\section{Acknowledgements}

Financial supports from the Innovation and Entrepreneurship Program for National Student (201610346024), the Tri-Five Cultivating Project (2016XJSGWXM26) and the Competition Project for 17th National Student Challenge Cup of Extracurricular Academic Science and Technology Works from Hangzhou Normal University were grate fully appreciated.

\section{References}

Bennett AJ, Bending GD, Chandler D, Hilton S, Mills P. Meeting the demand for crop production: The challenge of yield decline in crops grown in short rotation. Biol Rev. 2012; 87: 52-71.

Choi HJ, Wang HY, Kim YN, Heo SJ, Kim NK, Jeong MS, Park $\mathrm{YH}$, Kim S. Composition and cytotoxicity of essential oil extracted by steam distillation from horseweed (Erigeron canadensis L.) in Korea. J Korean Soc Appl Biol Chem. 2008; 51: 55-59.

Curini M, Bianchi A, Epifano F, Bruni R, Torta L, Zambonelli A. Composition and in vitro antifungal activity of essential oils of Erigeron canadensis and Myrtus communis from France. Chem Nat Compd. 2003; 39: 191-94.

Hong ES, Nguyen DTM, Nguyen DH, Kim EK. Inhibition of melanogenesis by Erigeron canadensis via down-regulating melanogenic enzymes in B16F10 melanoma cells. Korean J Chem Eng. 2008; 25: 1463-66.

Park WS, Bae JY, Chun MS, Chung HJ, Han SY, Ahn MJ. Suppression of gastric ulcer in mice by administration of Erigeron canadensis extract. Proc Nutr Soc. 2013; 72: E263-63.

Pawlaczyk I, Czerchawski L, Kuliczkowski W, Karolko B, Pilechi W, Witkiewicz W, Gancarz R. Anticoagulant and anti -platelet activity of polyphenolic-polysaccharide preparation isolated from the medicinal plant Erigeron canadensis L. Thromb Res. 2011; 127: 328-40.

Sohn SH, Ko E, Oh BG, Kim J, Choi E, Kim SH, Kim Y, Shin M, Hong M, Bae H. Global gene analysis of Erigeron canadensistreated TNF-alpha-, IL-4- and IL-1 beta-stimulated A549 human epithelial cells. Ann Nutr Metab. 2009; 54: 227-35.

Sung J, Sung M, Kim Y, Ham H, Jeong HS, Lee J. Antiinflammatory effect of methanol extract from Erigeron canadensis L. may be involved with up-regulation of heme oxygenase-1 expression and suppression of NF kappa B and MAPKs activation in macrophages. Nutr Res Pract. 2014; 8: 352-59.

Wu CY, Shao S, Yan MM, Fu ML, Xu DM. Research on development chemical constituents of Erigeron canadensis L. China Pharm. 2015; 24: 1-3.

Xie JL, Polvi EJ, Shekhar-Guturja T, Cowen LE. Elucidating drug resistance in human fungal pathogens. Future Microbiol. 2014; 9: 523-42.

Zhang $\mathrm{HW}$, Bai XL, Wu BX. Evaluation of antimicrobial activities of extracts of endophytic fungi from Artemisia annua Linn. Bangladesh J Phamacol. 2012; 7: 249-57.

Zhang HW, Ruan CF, Bai XL. Isolation and antimicrobial effects of endophytic fungi from Edgeworthia chrysantha. Bangladesh J Pharmacol. 2015; 10: 529-32.

Zhang HW, Song YC, Tan RX. Biology and chemistry of endophytes. Nat Prod Rep. 2006; 23: 753-71.

Zhang HW, Ying C, Bai XL. Advancement in endophytic microbes from medicinal plants. Int J Pharm Sci Res. 2014; 5: 1589-1600.

Zhang HW, Ying C, Tang YF. Antimicrobial screening of endophytic fungi from Hypericum perforatum Linn. Pakistan J Pharm Sci. 2014; 27: 1153-56. 


\section{Your feedback about this paper}

1. Number of times you have read this paper 0

2. Quality of paper Click

3. Your comments

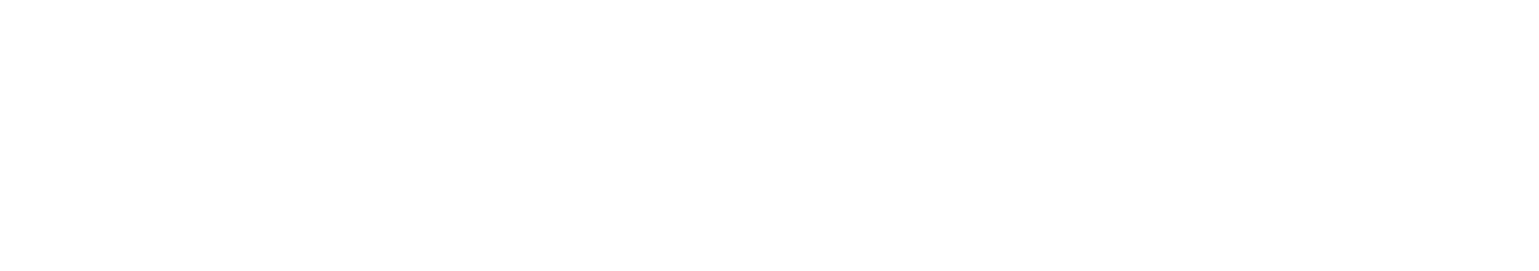

